Статья с открытым доступом под лицензией CC BY-NC-ND (https://creativecommons.org/licenses/by-nc-nd/3.0/) Материалы Международной практической интернет-конференции «Актуальные проблемы науки»

Выпуск II, ноябрь 2019

ISBN 978-601-323-144-0

https://doi.org/10.31643/2019.027

Арлен Сатаров

Кыргызский государственный университет геологии, горного дела и освоение природных ресурсов имени Академика У. Асаналиева. Кыргызстан.

\title{
Ускоренный метод определения склонности нержавеющей стали к межкристаллитной коррозии
}

\begin{abstract}
Абстракт: Абстракт: Данная работа заключается в раскрытии активных методов определения склонности нержавеющей стали к межкристаллической коррозии. Так же дается четкое определение для межкристаллитной коррозии и ее признаков наступления. И открыто указаны процессы обработки литейных материалов, которые дают некий повод вызова атаки междендритной коррозии, одним из которых является обработка нержавеющей стали в высоких температурах. При таких показателей можно узнать такие понятия, как акустическая, весовая и внешняя характеристика для стали. Все эти операции, процессы и испытания делаются ради того, чтобы проверить сталь на работоспособность. Показана работа выполненная лабораторных условиях, которая дала положительные результаты, при использовании одних из методов, основным критерием которого оказалась потеря веса.
\end{abstract}

Ключевые слова: Междендритная коррозия, потеря веса, акустические характеристики, критерии, атака, склонность.

\section{Введение}

Что такое межкристаллитная коррозия? Межкристаллитная коррозия иногда также называется «Междендритной коррозией». Это явление, точные механизмы которого обсуждались в течение почти полувека, в котором, при наличии растягивающего напряжения растрескивание может происходить вдоль границ зерен, и этот тип коррозии часто называют «коррозионным растрескиванием под межзерновым напряжением».

Обсуждение

«Межзерновой» или «Межкристаллический» означает между зернами или кристаллами. Межкристаллитная коррозия является одной из разновидностей структурной коррозии сплавов. Межкристаллитная коррозия (IGC) - это избирательная атака вблизи границ зерен нержавеющей стали, иначе говоря это истощения хрома в матрице сплава нержавеющей стали вблизи зернограничных карбидов хрома, выделяющих при термической обработки. Возникновение и развитие межкристаллитной коррозии нержавеющей стали определяется природой самой стали и ее состоянием, зависящим от условий термической обработки, а также природой действующей среды. Поэтому склонность нержавеющей стали к межкристаллитной коррозии, установленную при работе в определенной группе коррозионных сред, нельзя отнести к любым условиям работы материала. Из этого следует что, строго говоря, одного универсального стандартного определения склонности стали к межкристаллитной коррозии не может быть. Наблюдалось, например, что сталь не выдержавший испытания по ГОСТу, оказывалась вполне работоспособной в условиях эксплуатации в горячих газах, а материал выдержавший испытания в кипящей азотной кислоте, оказался нестойким в производственных условиях изготовления фенола. Более того, сопоставления параллельных испытаний по нескольким принятым методам не всегда дает совпадающие результаты. Назначение той или иной марки стали и метода ее обработки для работы в конструкции должно проводиться с 
учетом поведения этой стали в данной рабочей среде, которое может быть установлено, либо натурными испытаниями, либо ускоренными испытаниями, максимально приближающимися к натурным. Однако в производственных условиях безусловно необходим метод контроля запускаемой в производство партии материала, и этот метод должен быть достаточно быстрым и легко выполнимым. Контрольный метод испытания прежде всего должен отвечать на вопрос, возможна ли межзерновая коррозия данного материала. Вопрос в том, в какой мере поведения материала в контрольном испытании соответствует его поведению в условиях эксплуатации, должен решаться конкретно, применительно к этим условиям. Существуют следующие основные методы определения склонности нержавеющей стали к межкристаллитной коррозии. Их можно подразделить на химические, физические и электрохимические.

1. Обработка в кипящем растворе медного купороса и серной кислоты с последующим контролем образцов на звук, издаваемый при их падении на мраморную плиту, и оценкой состояния поверхности при изгибе наличие трещин. При этом производится также металлографический анализ определение изменения электросопротивление до и после коррозионного испытания. Продолжительность испытаний различными способами устанавливается от 15 до 2000 час.

2. Обработка кипящем 65\%-ном растворе азотной кислоты в течении 240 часов то есть по пять циклов по 48 часов с определением весовых потерь стали за каждый цикл испытания. Оценка качества стали устанавливается по сравнению со стандартными допустимыми величинами коррозионных потерь для данной марки стали.

3. Обработка в растворах смеси азотной и фтористоводородной кислот при 70-80 градусов по Цельсию в течение 2-12 часов с определением весовых потерь.

4. Электролитическое травление в растворе соляной кислоты с оценкой качества материала по характеру выявленной структуры.

Кроме того, сделана попытка разработать метод контроля работы стали в газовой среде, учитывающей особенности воздействия газовой среды при высоких температурах. Теории, объясняющие природу межкристаллитной коррозии, показывают что этот процесс связан с образованием второй фазы по границам зерен. В результате образования второй фазы на границе зерен создаются зоны с пониженной способностью к пассивированию при относительно малой площади, что приводит к интенсивной работе этих участков в качестве анодов. Прямые электрохимические исследования поддерживают анодный характер работы пограничных участков. Если считать, межкристаллитная коррозия может также определится относительно высокой растворимостью пограничных участков относительно высокой растворимостью пограничных участков, например, второй фазы или зоны, обедненной хромом за счет выпадения второй фазы, то и тогда процесс химического растворения усиливается электрохимическим путем, вследствие структурной и химической неоднородности поверхности. Применяемые для контрольных испытаний растворы, являясь пассиваторами, а также катодными деполяризаторами для основного зерна, усиленно растворяют активную пограничную зону. К таким растворам относится также исследованный раствор азотной кислоты с отрицательными ионами фтора.

Испытание в зависимости от толщины материала проводится в течение 15-20 час. Критерием оценки служит звук, издаваемый при падении образцов, обработанных в указанном растворе, и состояние поверхности образцов после изгиба. Другой метод испытания путем обработки в горячем растворе 10\%-ной азотной кислоты с добавкой 3\%-го фтористого натрия был введен в практику контроля сварных швов. В США в качестве стандартного метода установлено испытание в кипящем 65\%-ном растворе азотной кислоты. Параллельно испытания разными методами в растворах $\mathrm{HNO}_{3}$; $\mathrm{H}_{2} \mathrm{SO}_{4} ; \mathrm{CuSO}_{4} ; \mathrm{HNO}_{3}+\mathrm{HF}$, показали хорошее совпадение методов для большого количества сплавов с различной степенью чувствительности к межкристаллитной коррозии. В случае испытания сварных швов сходимостью результатов была хуже. Установлено, что высокая чувствительность к межкристаллитной коррозии, вызванная с образованием карбидов, обнаруживается любым методом. Небольшая склонность к межкристаллитной коррозии, вызванная например, карбидообразованием при сварке, наиболее легко обнаруживается в растворе $\mathrm{HNO}_{3}$. Чем при испытании в сернокислом растворе $\mathrm{CuSO}_{4}$, но оба указанных метода уступают в том случае испытанию в растворах $\mathrm{HNO}_{3}+\mathrm{HF}$. Чувствительность к межкристаллитной коррозии, вызванная образованием у - фазы, обнаруживается при кипячении в азотной кислоте и не выявляется в растворах $\mathrm{H}_{2} \mathrm{SO}_{4}, \mathrm{CuSO}_{4}, \mathrm{HNO}_{3}+\mathrm{HF}$. Это имеет место для малоуглеродистой стали и особенно сталей, содержащих молибден или ниобий, или оба элемента вместе. 
В настоящей работе исследовалось поведение нержавеющей стали, чувствительной к межкристаллитной коррозии, в растворах азотной кислоты с ионами фтора. Исследование было поставлено с целью изыскания быстрого и легко выполняемого способа определения склонности стали к межкристаллитной коррозии. Основным критерием оценки стали при испытании в растворах $\mathrm{HNO}_{3}+\mathrm{HF}$, по литературным данным, является потеря веса. Применяются однако, также испытания образцов на изгиб и межкристаллитное исследование.

\section{Метод}

Провели исследование на выявление склонности нержавеющей стали к межзерновой коррозии. Для начало взяли взвешенные на технических весах образцы сталей. В пяти пронумерованных емкостей подготовили по 20 мл растворов азотной кислоты со следующими процентными концентрациями: $10 \%, 15 \%, 20 \%, 25 \%, 30 \%$, с добавкой NaF объемами: $50 \mathrm{Mг}, 70 \mathrm{Mг}$, 100мг, 150мг, 200мг соответственно. В подготовленные растворы отпустили образцы.

Межкристаллитное поражение образцов определяется по следующим признакам: звук образцов при падении, состояние поверхности, при изгибе образцов вокруг оправки радиус равен удвоенной толщине образца, визуально оценивается также состояние внешнего облика образца. Коррозия определяется потерей веса образцов.

В качестве основного критерия оценки результатов были приняты показатели изменения звука образцов при падении, состояние образца после изгиба. Через определенные промежутки времени, если точнее 20 минут, 40 минут, 60 минут, проводили испытания образцов при падении. Для этого вынимали образцы из емкостей и бросали на мраморный стол, отметили звук, затем образцы вновь поместили в емкости.

Показатели междендритной коррозии оцениваются в баллах:

$>$ Балл - 1, звук металлический, отсутствие трещин и рябизны при изгибе.

$>$ Балл - 2, звук приглушенный, рябизна и мелкие трещины.

$>$ Балл -3 , звук приглушенный, трещины или звук глухой, мелкие трещины.

$>$ Балл -4 , звук глухой, трещины.

После проведения экспериментов образцы взвесили. Экспериментальные данные были сведены в специальную таблицу, где цифрами указывались баллы. Были найдены потери в весе с помощи разности первоначальной и конечной массы.

Таблица 1. Результаты весовых и акустических характеристик нержавеющей стали

\begin{tabular}{|c|c|c|c|c|c|c|}
\hline $\begin{array}{l}\text { № } \quad \text { Номер } \\
\text { образцов }\end{array}$ & $\begin{array}{l}\text { Првоначальная } \\
\text { масса } \mathrm{m}_{1}\end{array}$ & $\begin{array}{l}\text { Конечная } \\
\text { масса } \mathrm{m}_{2}\end{array}$ & $\begin{array}{l}\text { Показ } \\
\text { через } 40 \\
\text { мин }\end{array}$ & $\begin{array}{l}\text { Показ } \\
\text { через } 60 \\
\text { мин }\end{array}$ & $\begin{array}{l}\text { Показ } \\
\text { через } 80 \\
\text { мин }\end{array}$ & $\begin{array}{l}\text { Потеря } \\
\text { весе }\end{array}$ \\
\hline 1 & 3,67 грамм & 3,21 & 16 & 26 & 26 & 0,46 \\
\hline 2 & 3,80 грамм & 3,43 & 16 & 26 & 36 & 0,37 \\
\hline 3 & 3,55 грамм & 3,11 & 26 & 26 & 36 & 0,44 \\
\hline 4 & 3,78 грамм & 3,26 & 26 & 36 & 46 & 0,52 \\
\hline 5 & 3,34 грамм & 2,54 & 36 & 36 & 46 & 0,8 \\
\hline
\end{tabular}

\section{Вывод}

На данной статье мы продемонстрировали свои исследования, насчет склонности нержавеющей стали к межкристаллитной коррозии. Над нами было проверено один из основных методов выявления. Наши результаты показали, что при междендритной коррозии происходят ряд изменений, таких как потеря веса, акустические изменения и механически износ испытуемого материала. Мы были полностью удовлетворены своими показателями.

\section{Благодарность}

Данная работа была проведена при поддержке кафедры Металлургии Кыргызского Государственного Университета геологии, горного дела и освоение природных ресурсов им. Академика У. Асаналиева. 


\author{
Arlen Satarov \\ Kyrgyz State University of Geology, Mining and Natural Resources Development named \\ after Academician U. Asanaliev. Kyrgyzstan. \\ E-mail: arlensatarov5@gmail.com \\ ORCID ID: 0000-0003-3268-5983
}

\title{
Accelerated method for determining the tendency of stainless steel to intergranular corrosion
}

\begin{abstract}
This work should identify active methods for determining the tendency of stainless steel to intergranular corrosion. A clear definition is also given for intergranular corrosion and its signs of occurrence. And the processing processes of foundry materials are openly indicated, which gives some reasons to cause attacks of interdendritic corrosion, one of which is the processing of stainless steel at high temperatures. With the help of such indicators you can learn such concepts as acoustic, weight and external characteristics of steel. All these operations, processes and tests are carried out in order to check the quality of steel. Shown is the work performed in the laboratory, which gave positive results using one of the methods, the main criterion of which was weight loss.
\end{abstract}

Keywords: Interdendritic corrosion, weight loss, acoustic characteristics, criteria, attack, propensity.

Ссылка на данную статью: Сатаров А. (2019), Ускоренный метод определения склонности нержавеющей стали к межкристаллитной коррозии. Материалы Международной практической интернет-конференции «Актуальные проблемы науки» / Materials of International Practical Internet Conference "Challenges of Science". ISBN 978601-323-144-0. Выпуск II, 2019. Стр.: 137- 140. https://doi.org/10.31643/2019.027

\section{Литература}

[1] Алмакучукова Г. М., Мейманова Ж. С. «Коррозия и защита металлов» 2018 г.

[2] Бирбилис Н., Хинтон Б. «Основы металлургии алюминия» 2011 г.

[3] Виноградов Ю. М. «Коррозия и износ металлов» труды 27 выпуск 1959 г.

[4] Клинов И. Я., Молоканов А. В., Удыма П. Г. «Химические оборудования в коррозионностойком исполнении» 1970.

[5] Заруг О. С., Седрикс А. Ж. «Справочный модуль в области материаловедения» 2017 г. 